\title{
Improved Electric Strength and Space Charge Characterization in LDPE Composites with Montmorillonite Fillers
}

\author{
Ruijin Liao, ${ }^{1}$ Ge Bai, ${ }^{1}$ Lijun Yang, ${ }^{1}$ Huanchao Cheng, ${ }^{2}$ Yuan Yuan, ${ }^{1}$ and Jianxin Guan ${ }^{2}$ \\ ${ }^{1}$ State Key Laboratory of Power Transmission Equipment \& System Security and New Technology, Chongqing University, \\ Shaping Ba District, Chongqing 400044, China \\ ${ }^{2}$ China Electric Power Research Institute, Beijing 100192, China
}

Correspondence should be addressed to Ge Bai; baige0409@sina.com

Received 16 September 2013; Accepted 24 October 2013

Academic Editor: Wenjie Mai

Copyright (C) 2013 Ruijin Liao et al. This is an open access article distributed under the Creative Commons Attribution License, which permits unrestricted use, distribution, and reproduction in any medium, provided the original work is properly cited.

\begin{abstract}
Space charge distribution and breakdown strength were investigated in composites of low density polyethylene (LDPE) and various contents of montmorillonite (MMT). The disperse performance of MMT in LDPE was observed with scanning electron microscopy (SEM) and X-ray diffraction. For MMT concentration of $1 \mathrm{wt} \%$, the better intercalation of LDPE into MMT interlayers and the tighter interface structure between polymer-filler were observed, relative to MMT concentration of 3 and 5 wt $\%$. Space charge profiles were obtained using the pulsed electroacoustic (PEA) method. Less space charge accumulated in the LDPE/MMT with MMT content of $1 \mathrm{wt} \%$ than that in pure LDPE, and space charge in the central of LDPE/MMT was much more uniformly. On the other hand, when MMT concentration was up to 3 and $5 \mathrm{wt} \%$, large amounts of heterocharges were accumulated in the sample bulk. In MMT doped samples the dielectric strength increased up to a maximum at $1 \mathrm{wt} \%$ loading, and then decreases at 3 and $5 \mathrm{wt} \%$.
\end{abstract}

\section{Introduction}

Polyethylene is well known for its excellent electrical and mechanical properties which makes it an attractive insulating material for cable. The performance of polyethylene is a subject that has presented an increased activity in the last two decades. The major advantages are excellent electrical properties such as high breakdown strength, extremely low conductivity, and low dielectric loss. However, space charge formation in polymeric materials as one of the main problems in the development of cables, which strongly affect the degradation process and breakdown strength, due to accumulated charges causes the distorting of electric field severely and initiates the electric tree growth to part of the material being overstressed [1]. In recent decades, nanomaterial modification has developed rapidly in the field of dielectric materials. These inorganic fillers have been found to have a beneficial effect in improving the dielectric properties [2-4]. Among these, fillers have been used to improve the breakdown strength and reduce the possibility of tree generation. It was shown that low density polyethylene (LDPE) mixed with nanofiller could enhance the resistivity and reduce space charge accumulation [5-7].

In polymer-layered silicate nanocomposite systems, the proper addition of layered silicates leads to a great improvement in the properties of the matrix such as thermal stability and mechanical performance $[8,9]$. For insulating dielectric material, experiments have proven that the addition of an appropriate amount of montmorillonite (MMT) to silicone rubber, polypropylene, polyethylene, and ethylene-vinyl acetate (EVA) produces the nanocomposite with improved ability to inhibit electrical tree development as well as enhanced breakdown strength and heat resistance [10-13]. However, the influence of MMT dispersion morphology on the space charge formation and breakdown strength is rarely reported. In the present study, various contents of MMT particles were added to low density polyethylene (LDPE) via melt intercalation method, and the effect of dispersion of MMT on space charge distribution and breakdown strength was discussed. The purpose of this paper is to reveal the effects 


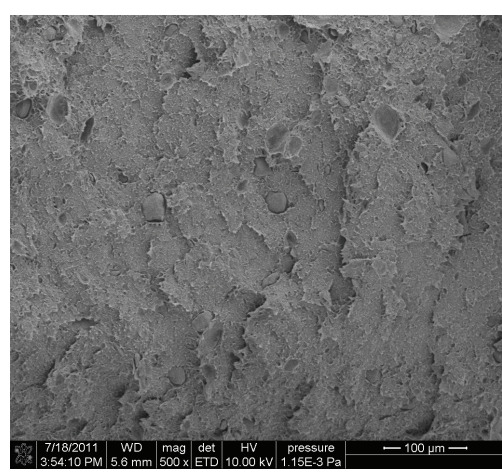

(a)

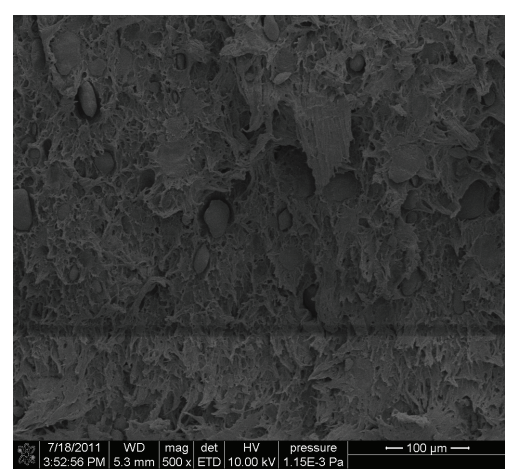

(b)

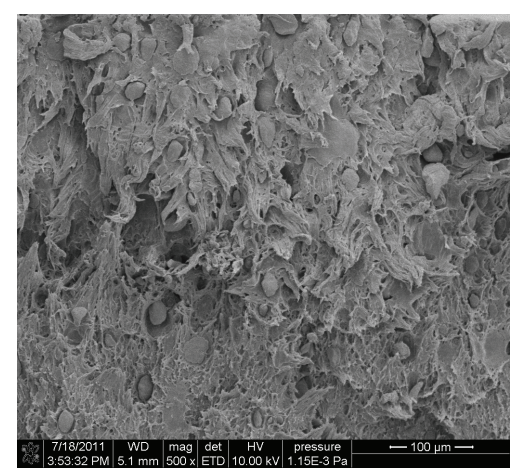

(c)

FIGURE 1: SEM analysis of LDPE doped with various amounts of MMT: (a) $1 \mathrm{wt} \%$, (b) $3 \mathrm{wt} \%$, and (c) $5 \mathrm{wt} \%$.

of space charge suppression as well as the influence of MMT dispersion state on charge formation and breakdown strength in LDPE/MMT composite.

\section{Material and Methods}

Low density polyethylene (LDPE $2426 \mathrm{H}$, density: $0.9227 \mathrm{~g} /$ $\mathrm{cm}^{3}$, melt index: $1.0 \mathrm{~g} / 10 \mathrm{~min}$ ) was purchased by Lanzhou Petrochemical Co., Ltd. (Gansu, China). A natural montmorillonite (Nanomer I.31PS, Nanocer) clay surface modified with octadecylamine and silane coupling agent was used as the reinforcement filler. The nanocomposite was prepared by melt intercalation method. LDPE with MMT were developed by melt blending and extrusion graining with twin-screw extruder at $443 \mathrm{~K}$. Then, films were obtained by hot compression. The mold temperature was $443 \mathrm{~K}$ under a pressure of $15 \mathrm{MPa}$ for 10 minutes. The pure LDPE was subject to the same process to be used as a reference. All the specimens were thermally treated for $48 \mathrm{~h}$ at $333 \mathrm{~K}$ before any measurement to ensure a stable reference state. The LDPE modified by MMT content of 1,3 , and $5 \mathrm{wt} \%$ were named as PEM1, PEM3, and PEM5.

The microstructures were carried out with a Rigaku $\mathrm{X}$-ray generator $(\mathrm{Cu} \mathrm{K} \alpha$ radiation with $\lambda=1.5406 \AA)$ (Tokyo, Japan) at the room temperature and a Field-emission Scanning Electron Microscope (FEI Nova 400 nano SEM, Hongkong). The diffractograms were scanned in the $2 \theta$ range of $2.0-10^{\circ}$ at a rate of $2^{\circ} / \mathrm{min}$. The composites were fractured first in liquid nitrogen and a thin layer of gold was sputtered onto the cross-sectional surface before SEM observation. Volume resistivity of samples was evaluated by the electrical resistivity tester (PC68, Shanghai). AC breakdown voltage was measured by self-made equipment according to IEC 60241-1:1998. Electrodes were made from copper. The space charge distributions were measured with the pulsed electroacoustic (PEA) method. The pea system used in this study has a pulsed voltage of up to $200 \mathrm{~V}$ with a width of $5 \mathrm{~ns}$. Electrodes were the grounded $\mathrm{Al}$ plate and the $\mathrm{Cu}$ plate connected to a high-voltage dc source. Silicon oil was used as an acoustic coupling agent to make a good acoustic contact between the measured electrode and the sample surface. The sample was subjected to a negative $-50 \mathrm{kV} / \mathrm{mm}$ of direct current field at room temperature.

\section{Results and Discussion}

3.1. The Dispersion of MMT in LDPE Matrix. Scanning electronic microscopy (SEM) is an efficient tool to investigate the morphology of the polymer/clay silicate composites, because information of the morphology of polymer matrix as well as of the fillers and the adhesion between them can be simultaneously assessed at the microscale level [14]. The dispersion of MMT fillers was examined by SEM. Figure 1 shows micrographs of LDPE specimens containing various contents of MMT. From both these images, it is evident that the fillers represent plat-like with high specific surface area, which span a wide size rang $(5 \mu \mathrm{m}-40 \mu \mathrm{m}$ are visible here), and that they are uniformly distributed throughout the polymer matrix. The MMT sheets were found to be increasing with the increase in filler content. It is worthwhile to note that the combination between MMT and LDPE is different. In Figure $1(\mathrm{a})$, at the addition content of $1 \mathrm{wt} \%$, the MMT sheet is inlaid in the LDPE closely and the bond between them is very good. With the increase of the amount of MMT, the resinparticle interfacial combination becomes weak, because in the area of interface there are large amounts of gaps between them as shown in Figures 1(b) and 1(c).

Figure 2 illustrates the XRD patterns of the LDPE composites with different clay contents. According to the Bragg equation, $2 d \sin \theta=n \lambda$, the average distance between MMT layers, $d_{001}$, can be calculated by the value of $2 \theta$ corresponding to the diffraction peak position of the (001) crystal plane. Table 1 shows the changes in the interlayer spacing for pure MMT and LDPE/MMT composites. The peak value of $2 \theta$ for MMT was 4.32, which was bigger than that of LDPE/MMT specimens. This indicated that the interlayer distances have increased after blending with LDPE from 2.04 nm for MMT, to 2.14, 2.68, and $2.99 \mathrm{~nm}$ for PEM5, PEM3, and PEM1, respectively. The changes of basal spacing reflect the intercalation stages of LDPE molecular chains into 


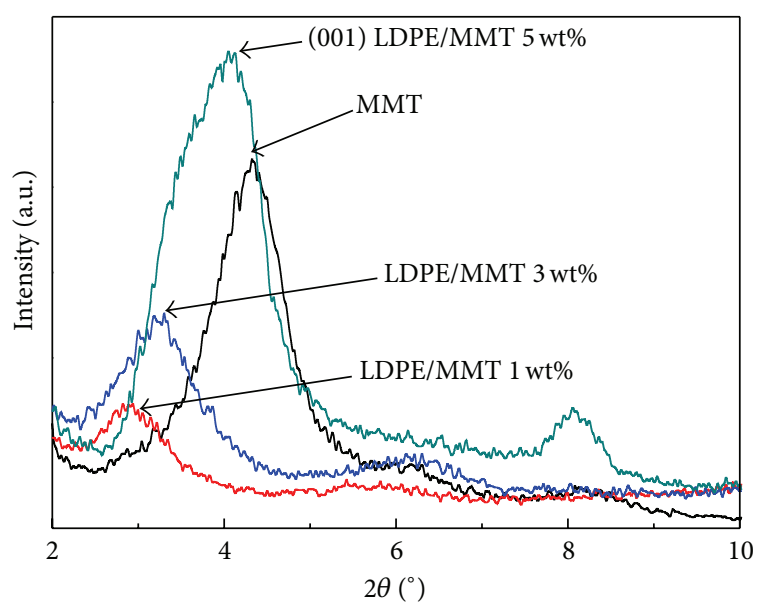

FIGURE 2: XRD patterns of the MMT, LDPE/MMT composites containing 1,3 , and $5 \mathrm{wt} \%$ MMT.

TABLE 1: $2 \theta$ and $d_{001}$ corresponding to the diffraction peak of (001) plane.

\begin{tabular}{lcccc}
\hline Sample & MMT & PEM1 & PEM3 & PEM5 \\
\hline $2 \theta\left(^{\circ}\right)$ & 4.32 & 2.95 & 3.3 & 4.12 \\
$d_{001}(\mathrm{~nm})$ & 2.04 & 2.99 & 2.68 & 2.14 \\
\hline
\end{tabular}

interlayer spaces of clay. However, PEM1 shows the biggest interlayer distance $d_{001}$. That is to say, polyethylene chains to penetrate into clay interlay more easily in PEM1 and excess addition of MMT will be disadvantageous to dispersion.

3.2. AC Breakdown Voltage and Volume Resistivity. The thickness of samples prepared for volume resistivity and AC breakdown test was about $100 \mu \mathrm{m}$. Volume resistivity can satisfy criteria's initial estimation of quality of insulating materials because it is sensitive on quality of manufacturing, content of all products, and additives. The volume resistivity $\rho V$ variation versus different clay contents is given in Figure 3. The value of each sample was measured 6 times. The applied voltage was $\mathrm{DC} 1 \mathrm{kV}$. The increase in volume resistivity varies monotonically with MMT loading level, and the value of $\rho V$ for pure LDPE was $2.3 \times 10^{17} \Omega \cdot \mathrm{cm}$ increased to $4.1 \times$ $10^{17} \Omega \cdot \mathrm{cm}$ for the $5 \mathrm{wt} \% \mathrm{MMT}$ doping. The increase of volume resistivity was caused by the decrease of conduction current, which is correlated to the charge mobility [15]. It is indicated that the MMT sheet can reduce charge carrier mobility as the phenomenon is similar to "barrier effect" in the LDPE matrix. In LDPE/MMT composite, the huge area of the particlepolymer interface may hinder the movement of the charges in the materials, which may cause the reduction of the electrical conductivity and consequently the volume resistivity.

As an attractive cable insulating material, one major objective of fillers in polyethylene is to improve electrical properties such as its breakdown strength. Therefore, shortterm power frequency $(50 \mathrm{~Hz})$ breakdown strength has been investigated. Applied voltage was raised at the rate of $500 \mathrm{~V} / \mathrm{S}$. The schematic diagram of electrodes for breakdown voltage

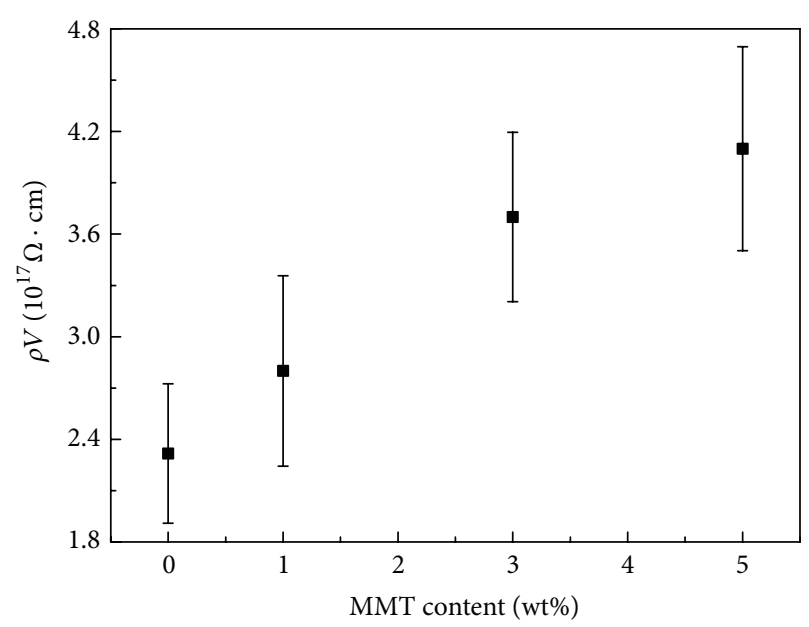

FIGURE 3: The change of volume resistivity for LDPE and composites.

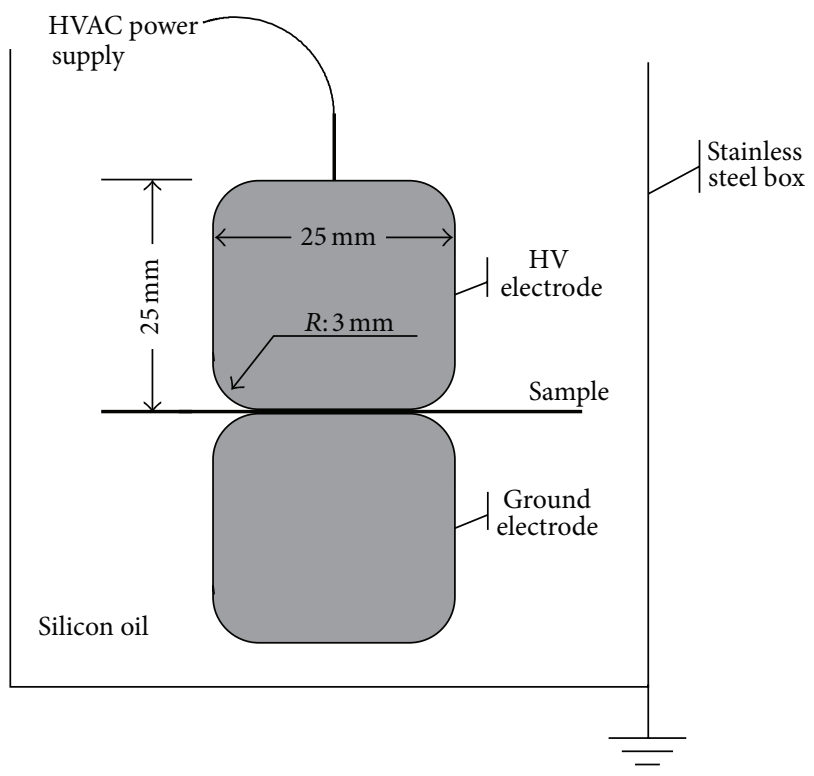

FIGURE 4: Sketch map of the AC breakdown test electrode.

measurement is shown in Figure 4. The diameter and height of electrodes were both $25 \mathrm{~mm}$. A copper bar was connected to HV electrode with HVAC power. In this testing, the sample was immersed in silicon oil in the stainless steel box.

The Weibull distribution is a general purpose reliability distribution used in the statistical analysis of breakdown data in insulating materials. The cumulative probability of failure for Weibull distribution can be written as

$$
P(E)=1-\exp \left[-\left(\frac{E}{\alpha}\right)^{\beta}\right]
$$

where $E$ is the experimental breakdown strength, $\alpha$ is called the scale parameter which represents the breakdown strength at the cumulative failure probability of $63.2 \%$, and $\beta$ is the shape parameter related to the dispersing of breakdown data. 


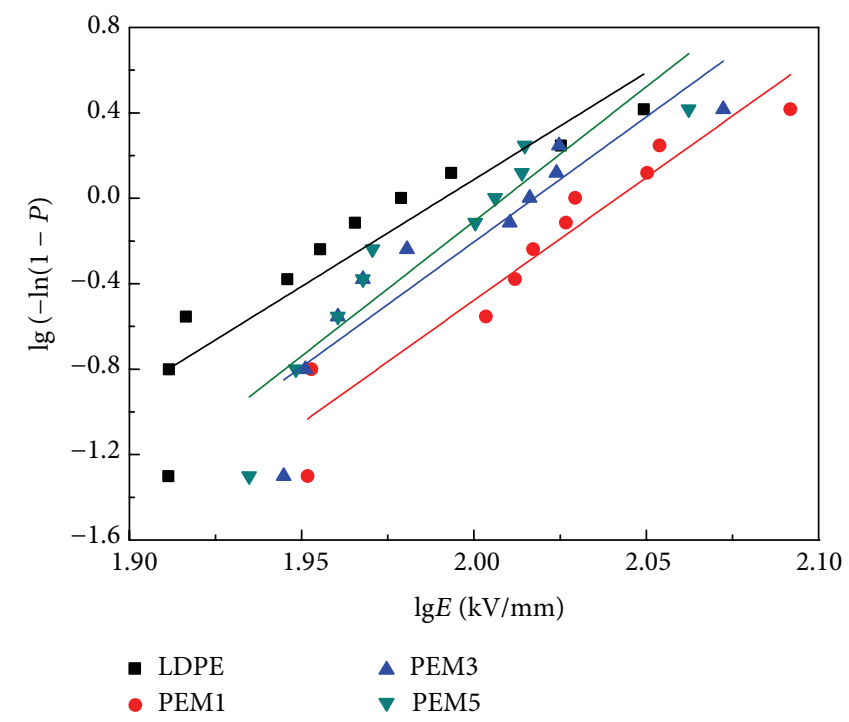

FIGURE 5: Weibull-distribution plot of breakdown for pure LDPE and LDPE/MMT composites.

TABLE 2: Results of the AC breakdown value $\alpha$ and the shape parameter $\beta$ for LDPE and LDPE/MMT samples.

\begin{tabular}{lcccc}
\hline & LDPE & PEM1 & PEM3 & PEM5 \\
\hline$\alpha(\mathrm{kV} / \mathrm{mm})$ & 97.9 & 110.3 & 104.1 & 102.1 \\
$\beta$ & 10 & 11.5 & 11.7 & 12.6 \\
\hline
\end{tabular}

Figure 5 depicts the Weibull plot of the AC breakdown strength. Data for $\alpha$ and $\beta$ are summarized in Table 2. It was found that LDPE doped with MMT systems have higher breakdown strengths than pure LDPE. Comparing the breakdown strength $\alpha$ value of pure LDPE and doped composite PEM1, $\alpha_{L} / \alpha_{P}=0.89$; thus, the incorporation of MMT particles into LDPE increases the breakdown strength by $11 \%$. The data also shows that MMT particles have the potential to improve the shape parameter $\beta$. Although the MMT doped composites all increase the AC breakdown strength compared to the unfilled LDPE, the breakdown strength of the LDPE/MMT composites increases up to a maximum at $1 \mathrm{wt} \%$ loading, and then decreases.

The phenomenon of dielectric breakdown in solids can be attributed to the destruction of dielectric by electronic or ionic charge carriers, which have acquired sufficient energy from the electric field. Charge carriers can be generated via charge injection from the electrodes and ionization within the materials. In this process, charges were trapped and detrapped from traps in the polymer matrix, which will cause molecular chains fragments to break [16], and partial discharge occurred which led to the formation of gas channels. For insulating polymer, the free path length is so short that electrons cannot gather enough energy to destroy macromolecules. So, it is commonly believed that the breakdown is initially from defects such as large void, in which electrons can gain enough energy. Voids are formed during manufacturing by evaporation of decomposition products in various chemical reactions taking place, or by impurities and additives decomposition, or by migration [17]. As already discussed before, the doping of MMT can constrain the charge carrier mobility. Moreover, nanoparticles can enhance partial discharge resistance in polymer [18]. This can reduce the impact of charge carrier to the polymer molecular chains, thereby increasing the breakdown strength. But at high filler loadings, nanoparticle aggregates can introduce large voids, in which the electron avalanche is more likely to happen and then erode the material.

3.3. Space Charge Accumulation under $-50 \mathrm{kV} / \mathrm{mm}$ of DC Electric Field. The thickness of samples prepared for space charge test was about $200 \mu \mathrm{m}$. The evolution of the space charge distribution along the specimens was shown in Figures 6 and 7. The two electrodes, positions are also illustrated. In LDPE specimen, immediately the voltage is applied, homospace charge is immediately injected from both anode and cathode in polymer, and moving into the bulk toward the opposite electrode. The injected positive and negative charges are observed in the bulk of the sample with a peak closes to the anode and cathode, respectively. Large number of negative heterocharges accumulated near the anode after $20 \mathrm{~min}$, meaning that the ionization process occurred in the sample. Figures 6(b)-6(d) show the charge formation in sample containing 1, 3, and $5 \mathrm{wt} \%$ of MMT. In Figures 6(b) and 7(b), at the presence of $1 \mathrm{wt} \% \mathrm{MMT}$, the accumulation of space charge decreases compared with pure LDPE and there are only a few negative charges in the sample. The space charge in the central of PEM1 sample is much more uniform than that in LDPE. This reveals that the addition of MMT filler plays a remarkable role to suppress space charge injection. When the amount of MMT is increased to 3 and $5 \mathrm{wt} \%$, significant amount of hetero space charge has been observed. Heterocharges come from the ionization of impurities in LDPE. In PEM3 and PEM5 samples, the bad dispersion of 


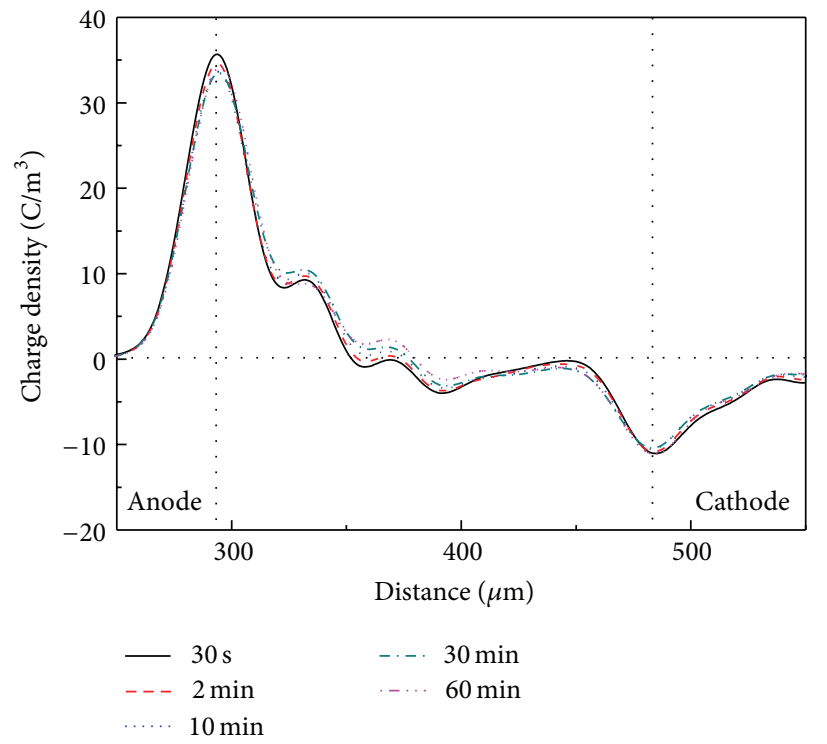

(a) LDPE

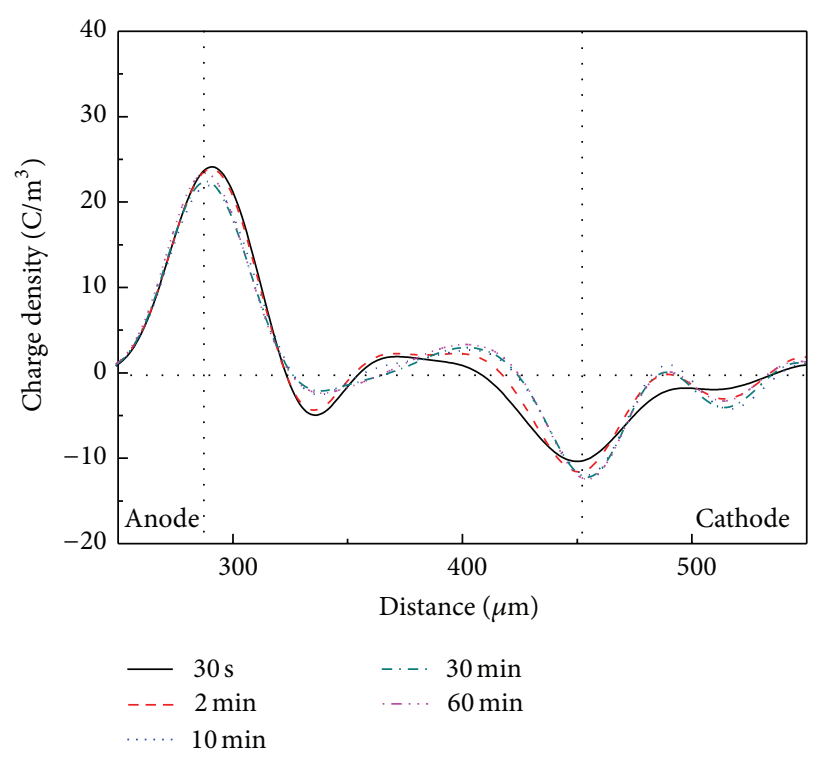

(c) PEM3

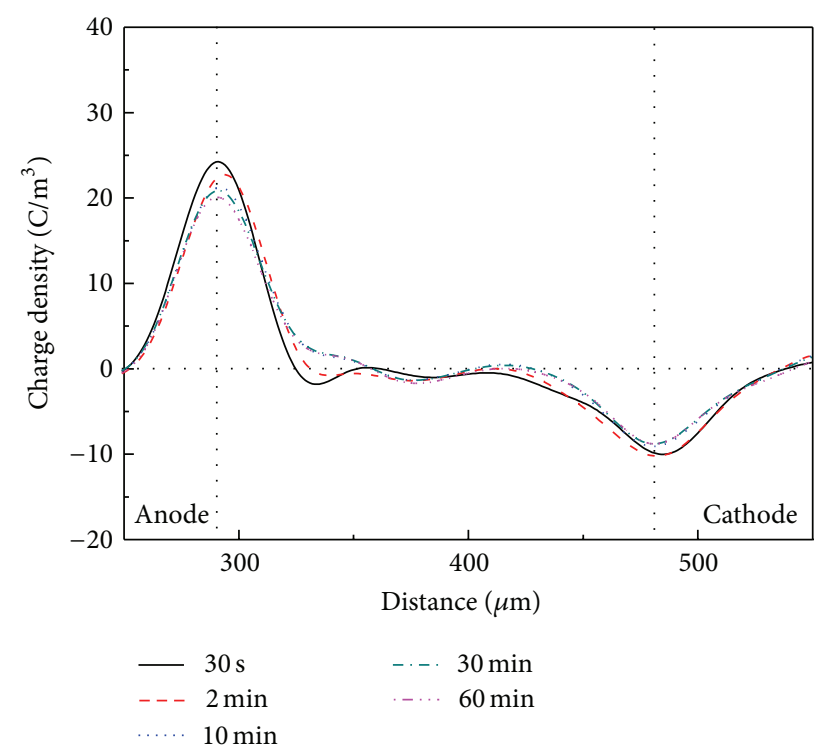

(b) PEM1

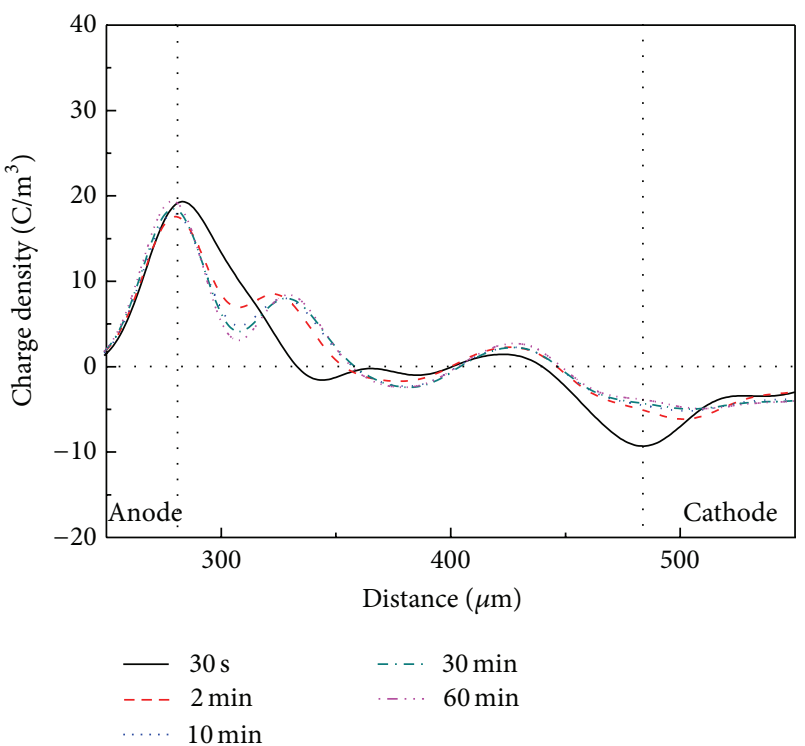

(d) PEM5

FIGURE 6: Space charge distribution under $-50 \mathrm{kV} / \mathrm{mm}$ in LDPE and LDPE/MMT composites.

particle in polymer matrix, results in many large voids located in the interface of particle-polymer. And the heterocharges are caused by discharges in voids within the materials.

The decay rate of space charge in MMT doped specimens is less than that in LDPE in Figure 7. This is mainly because MMT doping can generate enormous interface area due to their huge specific surface area, which may increase the density and depth of the trapping state. Space charge trapped at the interface between MMT and LDPE requires more energy for detrapping, and process of decaying requires more time.

In order to reveal the space charge suppression effect in PEM1 composite, the author focuses on the limitation of charge carrier mobility by MMT particle. In PEM1 composite, the reason of space charge suppression mainly is the limitation of charge carrier mobility by MMT particle. When charges are injected from electrodes, they are immediately captured and restricted in the traps near the surface of the sample. The restricted homocharges form a charge injection blocking and then raise the potential barrier for charge injection. In the bulk of the sample, positive and negative heterocharges caused by ionization are limited as a result of the low charge mobility, so heterocharges are reduced.

\section{Conclusions}

The effects of MMT addition on the microstructure and electrical properties of LDPE/MMT composites were studied. 


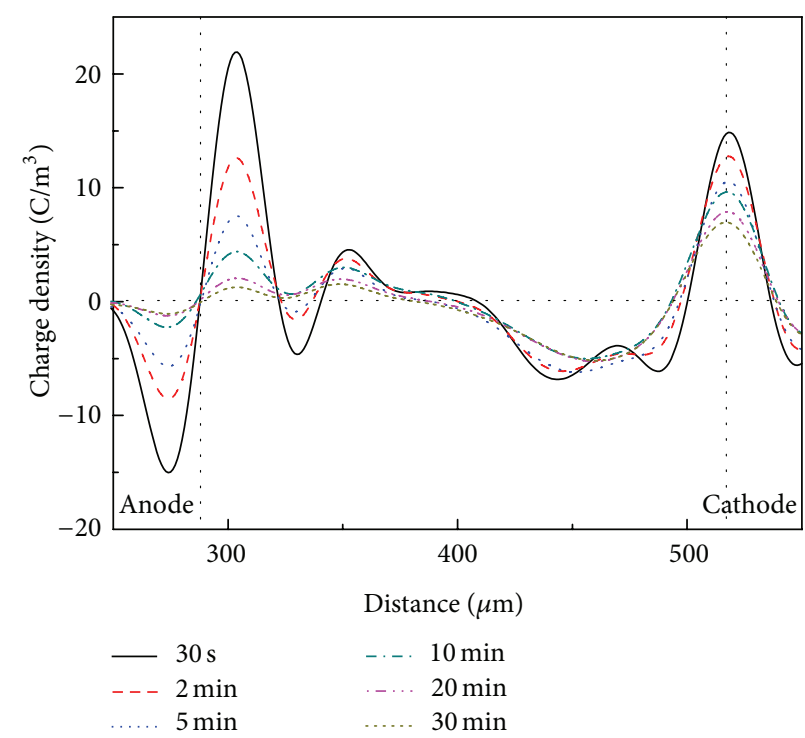

(a) LDPE

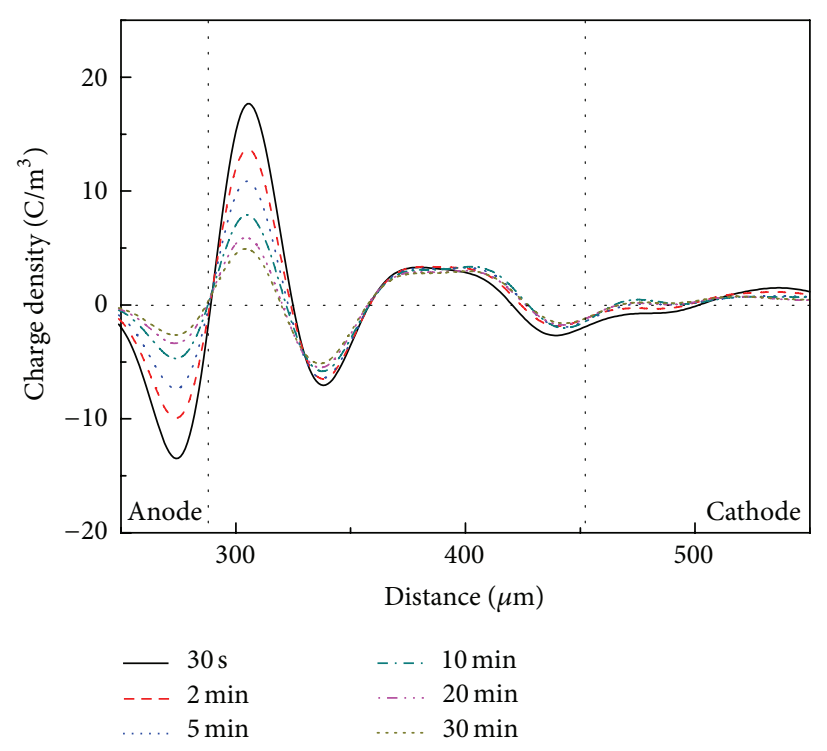

(c) PEM3

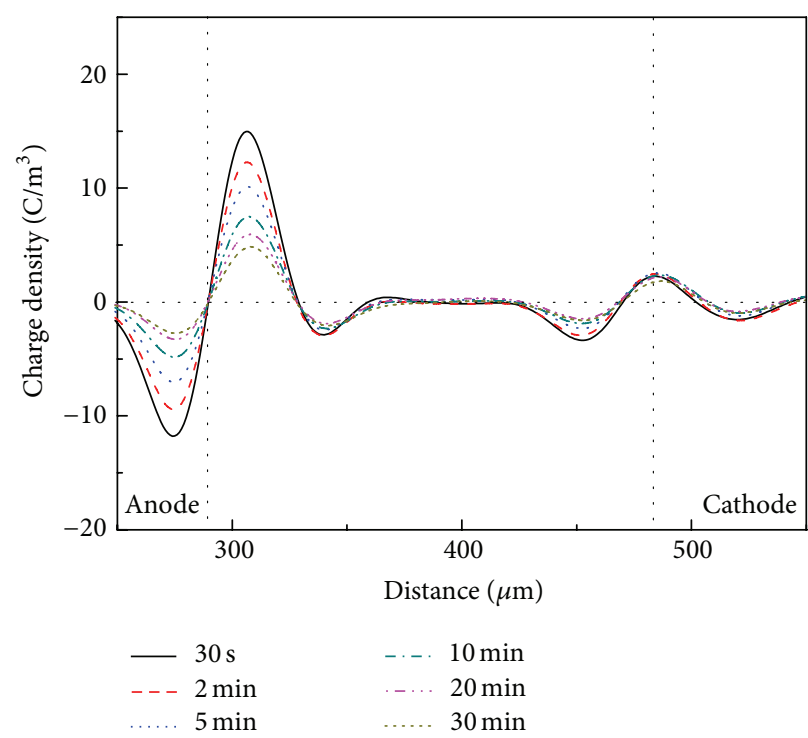

(b) PEM1

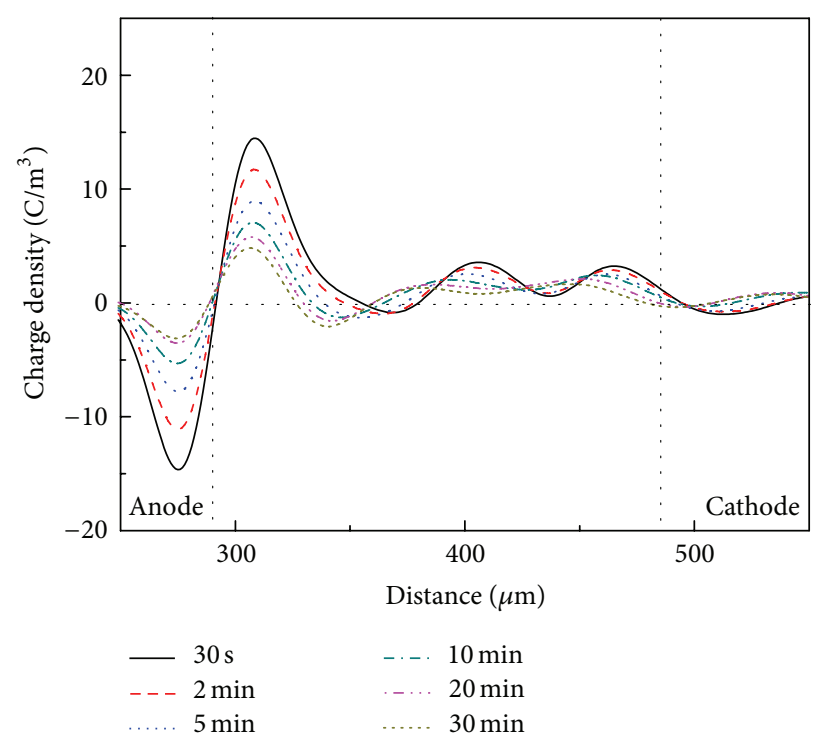

(d) PEM5

FIGURE 7: Space charge distribution after short circuit.

The MMT sheet can restrict charge carrier mobility in the polymer matrix. PEA test results show that LDPE blended with $1 \mathrm{wt} \%$ MMT can effectively decrease the accumulation and transfer of space charge. But in higher MMT concentration of 3 and $5 \mathrm{wt} \%$, large amounts of heterocharges were observed due to ionization. The breakdown electrical filed of LDPE/MMT composites increases up to a maximum at $1 \mathrm{wt} \%$ loading, and then decreases. Hence, the $1 \mathrm{wt} \%$ is the optimum MMT content for LDPE/MMT system.

\section{Conflict of Interests}

The authors declare that they have no financial or personal relationship with any people or any organization that may inappropriately influence their work, and that there is no professional or commercial interest of any kind in all of the commercial entities mentioned in their paper.

\section{Acknowledgment}

This research is supported by the national natural science foundation of China (51277187).

\section{References}

[1] T. L. Hanley, R. P. Burford, R. J. Fleming, and K. W. Barber, "A general review of polymeric insulation for use in HVDC cables," IEEE Electrical Insulation Magazine, vol. 19, no. 1, pp. 13-24, 2003. 
[2] R. Kurnianto, Y. Murakami, M. Nagao, N. Hozumi, and Y. Murata, "Treeing breakdown in inorganic-filler/LDPE nanocomposite material," IEEJ Transactions on Fundamentals and Materials, vol. 127, no. 1, pp. 29-34, 2007.

[3] X. Wang, D. M. Tu, C. Lei, and Q. G. Du, "Insulation performance and microstructure in modified polyethylene by MPE," Journal of Applied Polymer Science, vol. 107, no. 1, pp. 21-29, 2008.

[4] F. Tian, Q. Lei, X. Wang, and Y. Wang, "Effect of deep trapping states on space charge suppression in polyethylene/ $\mathrm{ZnO}$ nanocomposite," Applied Physics Letters, vol. 99, no. 14, Article ID 142903, 2011.

[5] T. Takada, Y. Hayase, Y. Tanaka, and T. Okamoto, "Space charge trapping in electrical potential well caused by permanent and induced dipoles for LDPE/MgO nanocomposite," IEEE Transactions on Dielectrics and Electrical Insulation, vol. 15, no. 1, pp. 152-160, 2008.

[6] X. Huang, P. Jiang, and Y. Yin, "Nanoparticle surface modification induced space charge suppression in linear low density polyethylene," Applied Physics Letters, vol. 95, no. 24, 3 pages, 2009.

[7] S. Li, G. Yin, and J. Li, "Breakdown performance of low density polyethylene nanocomposites," in Proceedings of the 10th IEEE International Conference on the Properties and Applications of Dielectric Materials (ICPADM '12), pp. 1-4, 2012.

[8] S. Pavlidou and C. D. Papaspyrides, "A review on polymer-layered silicate nanocomposites," Progress in Polymer Science, vol. 33, no. 12, pp. 1119-1198, 2008.

[9] S. Hakim, M. Safajou-Jahankhanemlou, and M. E. Zeynali, "Polyethylene nanocomposite prepared by a metallocene catalyst supported on MMT using a new pretreatment method," Journal of Polymer Research, vol. 20, pp. 1-10, 2013.

[10] M. Ahmad, H. Ahmad, N. Bashir et al., "Electrical treeing in silicone rubber/organo-montmorillonite," in Proceedings of the IEEE Annual Report Conference on Electrical Insulation and Dielectric Phenomena (CEIDP '12), pp. 898-901, 2012.

[11] E. Izci and N. Bowler, "Dielectric properties of isotactic polypropylene and montmorillonite nanocomposites," in Proceedings of the 10th IEEE International Conference on Solid Dielectrics (ICSD '10), pp. 1-4, July 2010.

[12] C. D. Green and A. S. Vaughan, "Polyethylene/montmorillonite nanocomposites: effect of masterbatch composition and maleic anhydride on AC electrical breakdown performance," in Proceedings of the International Conference on Solid Dielectrics (ICSD '07), pp. 364-367, July 2007.

[13] F. Guastavino, A. Dardano, G. C. Montanari, L. Testa, and F. Bellucci, "Electrical treeing in EVA-boehmite and EVAmontmorillonite nanocomposites," in Proceedings of the IEEE Electrical Insulation Conference (EIC '09), pp. 382-386, June 2009.

[14] R. Adhikari and G. H. Michler, "Polymer nanocomposites characterization by microscopy," Polymer Reviews, vol. 49, no. 3, pp. 141-180, 2009.

[15] J. A. Anta, G. Marcelli, M. Meunier, and N. Quirke, "Models of electron trapping and transport in polyethylene: currentvoltage characteristics," Journal of Applied Physics, vol. 92, no. 2, pp. 1002-1008, 2002.

[16] Z. Liu, R. Liu, H. Wang, and W. Liu, "Space charges and initiation of electrical trees," IEEE Transactions on Electrical Insulation, vol. 24, no. 1, pp. 83-89, 1989.
[17] K. Theodosiou, I. Vitellas, I. Gialas, and D. P. Agoris, "Polymer films degradation and breakdown in high voltage AC fields," Journal of Electrical Engineering, vol. 55, pp. 225-231, 2004.

[18] T. Tanaka, "Dielectric nanocomposites with insulating properties," IEEE Transactions on Dielectrics and Electrical Insulation, vol. 12, no. 5, pp. 914-928, 2005. 

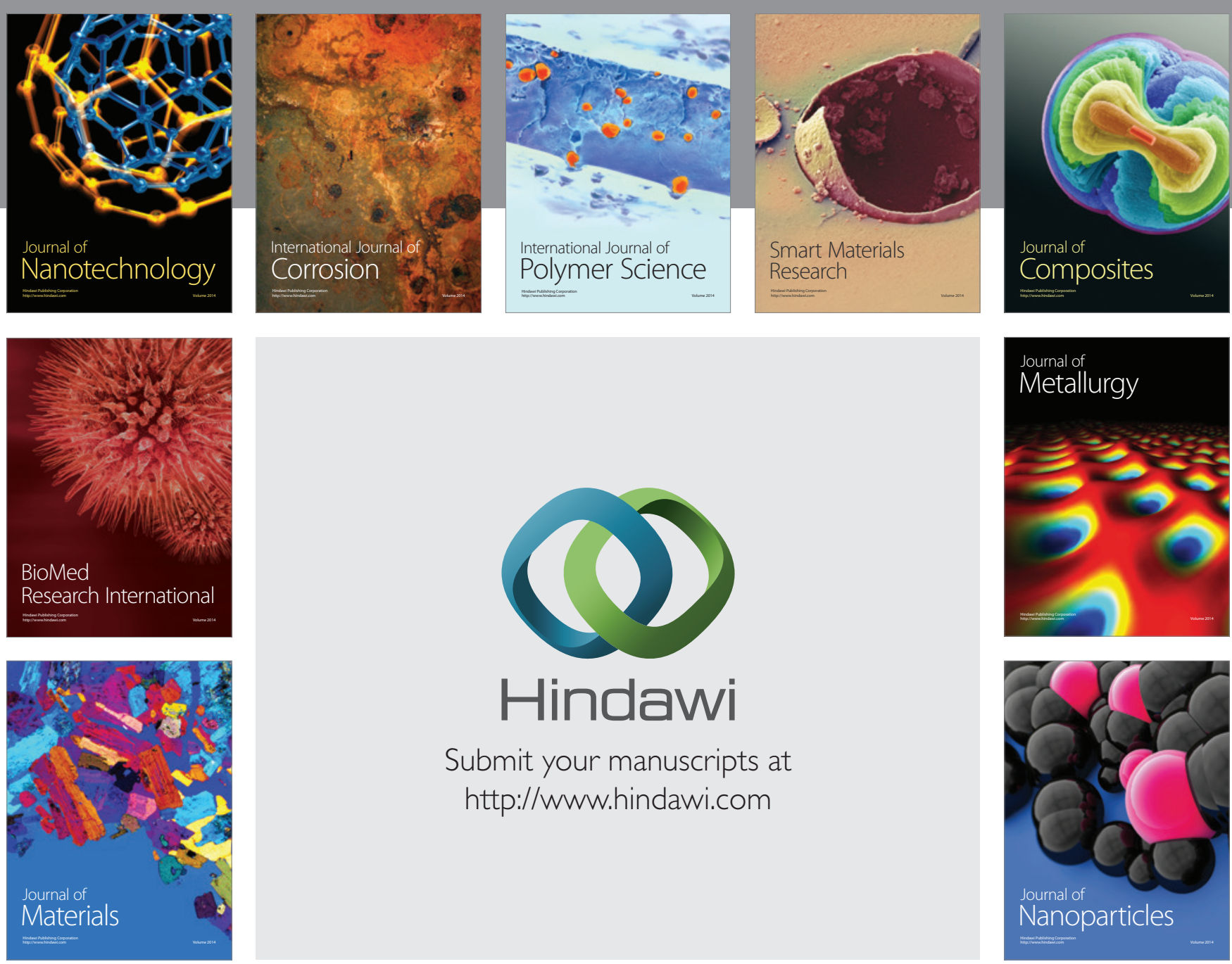

Submit your manuscripts at http://www.hindawi.com
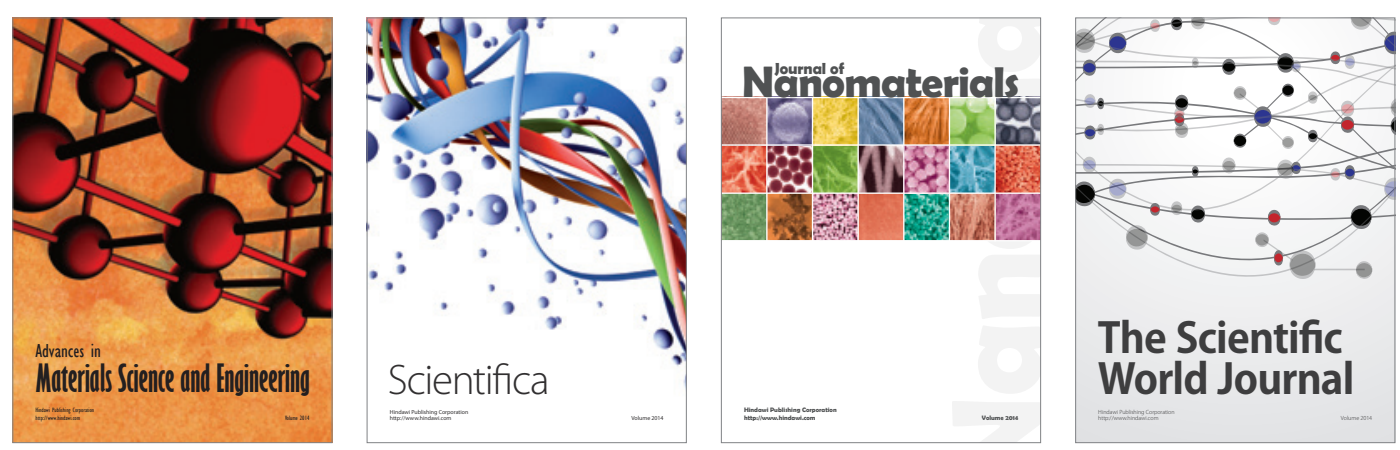

\section{The Scientific World Journal}
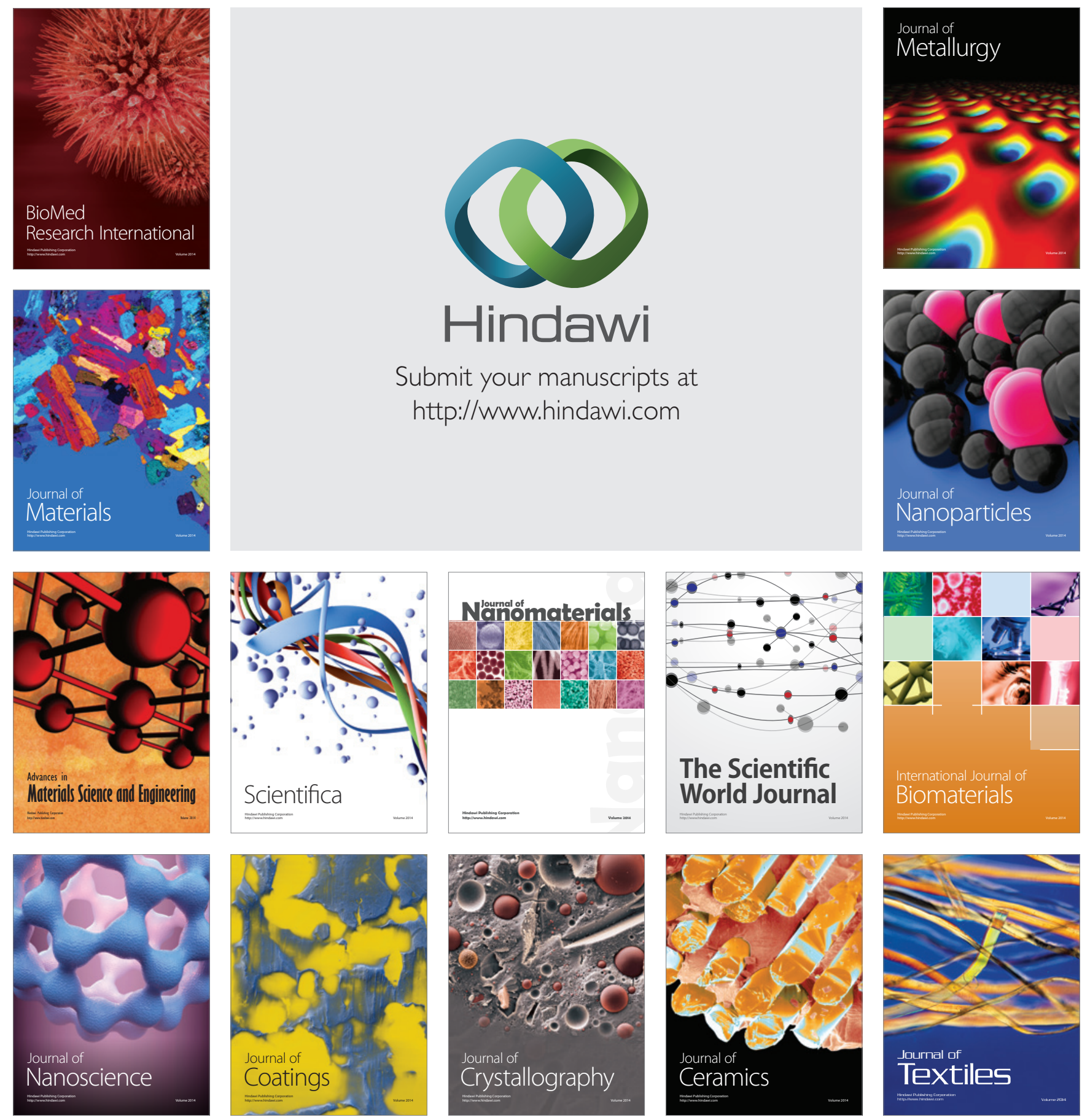